Revista de Derecho YACHAQ

ISSN: 1817-597x (impresa) / ISSN: 2707-1197 (en linea)

Centro de Investigación de los Estudiantes de Derecho (CIED)

Universidad Nacional de San Antonio Abad del Cusco

N. ${ }^{\circ} 10-2019$

[pp. 73-94]

Fecha de recepción: 12/08/19

Fecha de aceptación: 14/09/19

\title{
La protección de los datos personales en el sistema de reporte de créditos peruano
}

\author{
Personal Data Protection in the \\ Peruvian Credit Reporting System
}

\author{
Raúl Vásquez Rodríguez ${ }^{[*]}$
}

\begin{abstract}
RESUMEN: este trabajo analiza la interacción entre el tratamiento de información crediticia de las personas naturales a cargo de las centrales de riesgo, debido a su importancia para los agentes de mercado, y el derecho fundamental a la protección de los datos personales, profundizando en el trasfondo constitucional de los derechos involucrados, en las interpretaciones del Tribunal Constitucional y en la compatibilidad de objetivos respecto de la privacidad y la confidencialidad que existe entre la Ley $N .^{\circ} 27489$, Ley que regula las Centrales Privadas de Información de Riesgos y de Protección al Titular de la Información y la Ley N..$^{\circ}$ 29733, Ley de Protección de Datos Personales y su reglamento; interacción analizada por la Autoridad Nacional de Protección de Datos Personales en sus resoluciones directorales.

ABSTRACT: this work researchs the interaction between the personal credit data processing of natural people in charge of the Credit Risks Agencies, because of its relevance for stakeholders and the fundamental right for the personal data protection, deepening in the constitutional background of the involved rights, in the Constitutional Court statements and the compatibility whith the privacy and confidentiality targets that exists between the Law N. ${ }^{\circ}$ 27489, which regulates the Credit Risk Information Private Center and the Data Holder Protection Act, and the Law N. ${ }^{\circ} 29733$, law for the Personal Data Protection and its rulement; which is analyzed by Personal Data Protection Agency in its directoral judgments.
\end{abstract}

PALABRAS CLAVE: protección de datos, datos crediticios, centrales de riesgo.

KEYWORDS: data protection, credit data, credit risk agencies.

[*] Abogado y Magíster en Derecho de la Propiedad Intelectual y de la Competencia por la Pontificia Universidad Católica del Perú, con especialización en Derecho Administrativo por la Universidad de Salamanca. Miembro del Colegio de Abogados de Lima. Contacto: ravasquez78@yahoo.com 


\section{MARCO INTRODUCTORIO}

Entre los bienes más valiosos del mercado está la información de quienes intervienen en él, más aún en operaciones crediticias, en las que es inherente el riesgo de no devolución del dinero invertido, el llamado «riesgo crediticio» de la Ley N. ${ }^{\circ}$ 26702, Ley General del Sistema Financiero y del Sistema de Seguros y Orgánica de la Superintendencia de Banca y Seguros (Ley N. ${ }^{\circ}$ 26702) ${ }^{[1]}$, ya sea un préstamo u otra forma contractual lícita (Vilela, 2015, p. 28).

Dicha incertidumbre dificulta al agente decidir sobre el otorgamiento de créditos y sobre las condiciones a imponer para compensar tal riesgo (Figueroa, 2010, p. 11). Para superar tal vicisitud, se necesita información sobre la capacidad de endeudamiento y pago del potencial cliente y con ello, determinar su riesgo crediticio, lo cual le permitirá elegir cómo contratar o no hacerlo, basándose en datos objetivos del desenvolvimiento en el mercado del sujeto.
Reconociendo ello, el Tribunal Constitucional señaló que con la circulación de tal información, exacta y actual, crece la confianza en el sistema crediticio y se facilita el acceso a él de nuevos partícipes aptos para mercado, favoreciendo a los otorgantes de capital, a sus clientes, así como a la seguridad jurídica en el tráfico económico.

La Ley N. 26702 establece en su artículo 158 el registro llamado «Central de Riesgos» de la Superintendencia de Banca, Seguros y AFP, en el que la información financiera, crediticia, comercial y de seguros sobre los intervinientes en el mercado se consolida, siendo obligatoria su consulta previa al otorgamiento de un crédito y la remisión de dicha información por parte de las empresas del sistema financiero, según el artículo 159 de dicha ley; pudiendo desarrollarse tal sistematización y entrega de información por medio de entidades privadas, las Centrales Privadas de Información de Riesgos (CEPIR) ${ }^{[2]}$.

[1] Congreso de la República, 6 de diciembre de 1996. Glosario. Ley N. ${ }^{\circ}$ 27489, Ley General del Sistema Financiero y del Sistema de Seguros y Orgánica de la Superintendencia de Banca y Seguros. Diario Oficial El Peruano.

\section{«ANEXO-GLOSARIO}

$[\ldots]$

Riesgo crediticio: el riesgo de que el deudor o la contraparte de un contrato financiero no cumpla con las condiciones del contrato.»

[2] Congreso de la República, 6 de diciembre de 1996. Glosario. Ley N. ${ }^{\circ}$ 27489, Ley General del Sistema Financiero y del Sistema de Seguros y Orgánica de la Superintendencia de Banca y Seguros. Diario Oficial El Peruano.

Artículo 158. ORGANIZACIÓN DE LA CENTRAL DE RIESGOS E INFORMACIÓN QUE CONTENDRÁ. La Superintendencia tendrá a su cargo un sistema integrado de registro de riesgos financieros, crediticios, comerciales y de seguros denominado "Central de Riesgos», el mismo que contará con información consolidada y clasificada sobre los deudores de las empresas.

$[\ldots]$

Se registrará en la Central de Riesgos los riesgos por endeudamientos financieros y crediticios en el país y en el exterior, los riesgos comerciales en el país, los riesgos vinculados con el seguro de crédito y otros riesgos de seguro, dentro de los límites que determine la Superintendencia.

$[\ldots]$

\section{Artículo 159. OBLIGACIÓN DE SUMINISTRAR LA INFORMACIÓN RELEVANTE}

Las empresas de los sistemas financiero y de seguros deben suministrar periódica y oportunamente la información que se requiere para mantener actualizado el registro de que trata el artículo anterior. De contar con sistemas computarizados proporcionarán dicha información diariamente.

Toda empresa del sistema financiero antes de otorgar un crédito deberá requerir a la persona natural o jurídica que lo solicite, la información que con carácter general establezca la Superintendencia. En caso de incumplimiento, no podrá otorgarse el crédito. 
Con tal permisión para el manejo de información crediticia, surge el riesgo de recopilación indiscriminada de información personal, capaz de conducir a la saturación del sistema con información irrelevante para el mercado y a la ejecución de acciones invasivas para las personas naturales. A fin de prevenir dichos perjuicios y delimitar la función de las CEPIR, se promulga la Ley $\mathrm{N}^{\circ}$ 27489, Ley que regula las Centrales Privadas de Información de Riesgos y de Protección al Titular de la Información (Ley CEPIR).

Por su parte, la Ley N. ${ }^{\circ} 29733$, Ley de Protección de Datos Personales (LPDP) prioriza el derecho fundamental de las personas a la protección de sus datos personales y otros involucrados (intimidad, honor y reputación, principalmente), procurando por el debido manejo, por parte de terceros como las CE$\mathrm{PIR}$, de datos que hacen identificable a la persona.

Este artículo analiza las normas constituciona les referidas a la protección de datos personales y a la libertad de contratación, previo al repaso de las mencionadas leyes, para analizar lo resuelto en el Expediente N. ${ }^{\circ}$ 087-2018-JUS/DPDP-PS por la Dirección de Protección de Datos Personales (DPDP) y su superior jerárquico, la Dirección General de Transparencia, Acceso a la Información Pública y Protección de Datos Personales (DGTAIPD), que ejercen la Autoridad Nacional de Protección de Datos Personales (APDP); procedimiento llevado con Sentinel Perú S.A. (Sentinel), una de las CEPIR más grandes del mercado peruano ${ }^{[3]}$.

\section{DERECHOS CONSTITUCIONALES INVOLU- CRADOS}

Es necesario partir de los derechos fundamentales de las personas, así como de los derechos involucrados con la economía social de mercado, contenidos en la Constitución Política del Perú. Obedeciendo a la sistemática de nuestra carta magna, conviene iniciar los derechos fundamentales a la intimidad personal y familiar, de los numerales 6 y 7 de su artículo $2^{[4]}$.

El numeral 7 ofrece para la intimidad personal y familiar la garantía de prohibir el escudriñamiento y/o divulgación no deseada de los actos de las personas, contribuyendo a su inviolabilidad, así como al equilibrio necesario para su desarrollo individual y en sociedad (Fernández, 2004, p. 59); vale decir, establece una prohibición general, un impedimento para acciones de terceros respecto de la información del sujeto.

Por su parte, en el texto del numeral 6 de dicho artículo constitucional se aprecia la protección de la intimidad contra el suministro de información que pueda afectarla su intimidad, vale decir, acciones con la información del individuo en dominio de terceros, lo que hace que la integridad de su derecho dependa del comportamiento de aquellos.

Entonces, el derecho del numeral 6 marca una diferencia conceptual importante respecto del derecho del numeral 7, pues no consiste solo en la pasividad de la prohibición, sino que al consistir en el

\section{Artículo 160. CENTRALES DE RIESGOS PRIVADAS}

Es libre la constitución de personas jurídicas que tengan por objeto proporcionar al público información sobre los antecedentes crediticios de los deudores de las empresas de los sistemas financiero y de seguros y sobre el uso indebido del cheque.

$[\ldots] »$.

[3] Las resoluciones de primera y segunda instancia se encuentran disponibles en https://www.minjus.gob. pe/procedimientos-administrativos-sancionadores/

[4] Congreso Constituyente Democrático, 29 de diciembre de 1993, Constitución Política del Perú.

\section{Artículo 2. Toda persona tiene derecho:}

$[\ldots]$

6. A que los servicios informáticos, computarizados o no, públicos o privados, no suministren informaciones que afecten la intimidad personal y familiar.

7. Al honor y a la buena reputación, a la intimidad personal y familiar, así como a la voz y a la imagen propias. 
control de comportamientos ajenos, premune a la persona de la facultad de ejercer señorío sobre su información y de determinar qué se hace con ella (Lete del Río, 1996, pp. 176-177) a fin de no solo protegerse, sino de obligar a prevenir y revertir los efectos de actividades de terceros que, sin que lo haya consentido, expongan su intimidad.

Por ello, el derecho fundamental a la protección de datos personales (denominado también «autodeterminación informativa») se yergue autónomo, permitiendo controlar cualquier acto de tratamiento de su información personal mediante las facultades que le otorga (Castro, 2008, pp. 261262) o los procedimiento puestos a su disposición por los poderes públicos, lo que satisface la necesidad de equilibrio a favor del individuo en el actual contexto de circulación de información (Pérez Luño, 1996, pp. 23-24).

Habiendo sido reconocida en el derecho español con la Sentencia N. ${ }^{\circ}$ 292/2000, como «[...] poder de disposición y de control sobre los datos personales que faculta a la persona para decidir cuáles de esos datos proporcionar a un tercero, [...] y que también permite al individuo saber quién posee esos datos personales y para qué, pudiendo oponerse a esa posesión o uso» „5], la protección de los datos personales es reconocida y conceptualizada en el Perú a través de sentencias del Tribunal Constitucional como la recaída

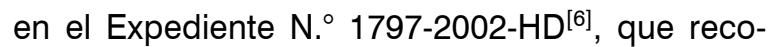
noce su autonomía respecto del derecho a la intimidad contemplado en el numeral 7 , gracias a los poderes que otorga sobre terceros.

Posteriormente, el supremo intérprete constitucional peruano reforzó el concepto de tal derecho fundamental, incidiendo en la facultad de oponerlo ante personas naturales o jurídicas, públicas o privadas, así como en la protección integral de las personas a través de su facultad de imperar sobre su información personal y las acciones de terceros sobre ella, como se aprecia en la sentencia del Expediente $\mathrm{N}{ }^{\circ}$ 4739-2007-PHD/TC ${ }^{[7]}$.

De otro lado, el numeral 14 del artículo $2^{[8]}$ de la Constitución da a las personas la libertad de contratar, conjugando voluntades en relaciones jurídicas patrimoniales (Chanamé, 2008, p. 60), teniendo como límite la licitud y el orden público. Este derecho se desarrolla en la Economía Social de Mer-

[5] Sentencia 292/2000, de 30 de noviembre de 2000.

[6] Sentencia del Tribunal Constitucional en el Expediente N. ${ }^{\circ}$ 1797-2002/HD, del 29 de enero de 2003:

3. [...] el derecho a la autodeterminación informativa no puede identificarse con el derecho a la intimidad, personal o familiar, reconocido, a su vez, por el inciso 7) del mismo artículo 2 de la Constitución. Ello se debe a que mientras que este protege el derecho a la vida privada, esto es, el poder jurídico de rechazar intromisiones ilegítimas en la vida íntima o familiar de las personas, aquel garantiza la facultad de todo individuo de poder preservarla controlando el registro, uso y revelación de los datos que les conciernen.

[7] Sentencia del Tribunal Constitucional en el Expediente N. ${ }^{\circ}$ 4739-2002/HD, del 15 de octubre de 2007:

2. [...] el derecho a la autodeterminación informativa consiste en la serie de facultades que tiene toda persona para ejercer control sobre la información personal que le concierne, contenida en registros ya sean públicos, privados o informáticos, a fin de enfrentar las posibles extralimitaciones de los mismos. Se encuentra estrechamente ligado a un control sobre la información, como una autodeterminación de la vida íntima, de la esfera personal.

3. [...] se busca proteger a la persona en sí misma, no únicamente en los derechos que conciernen a su esfera personalísima, sino a la persona en la totalidad de ámbitos [...].

[8] Congreso Constituyente Democrático, 29 de diciembre de 1993, Constitución Política del Perú.

\section{«Artículo 2. Toda persona tiene derecho:}

$[\ldots]$

14. A contratar con fines lícitos, siempre que no se contravengan leyes de orden público.» 
cado, como se ve en el artículo $59^{[9]}$, protegiendo la libertad de empresa, comercio e industria, sin perjudicar la salud, la seguridad pública y la moral, vale decir, los valores más importantes para el bienestar de la persona.

Por su parte, según el artículo 62 de la Constitución ${ }^{[10]}$, se permite el libre pacto respetando la normativa vigente, que incluye los derechos fundamentales de las personas y los límites que estos imponen. Dicho precepto constitucional se manifiesta en el derecho a elegir si contratar o no, con quién hacerlo, y la determinación autónoma de los términos contractuales (Kresalja y Ochoa, 2012, pp. 72-73), ejerciéndose así otros derechos como la libertad de comercio.

Para ejercer tal libertad en el ámbito de mercados importantes como el financiero, es importante del flujo de información crediticia, siguiendo lo explicado en la sentencia del Tribunal Constitucional en el Expediente $\mathrm{N} .^{\circ} 3700-2010-\mathrm{PHD} / \mathrm{TC}^{[11]}$, que implica el comportamiento actual e histórico de los sujetos de crédito, lo cual permite la adopción de decisiones adecuadas respecto del otorgamiento de créditos y genera más confianza entre los agentes del mercado, posibilitando el ejercicio de tal libertad entre los «buenos deudores» (Más, 2017, pp. 211-212), al poder acceder a créditos para efectuar actividades económicas.

Asimismo, el artículo 65 de la Constitución ${ }^{[12]}$ establece que el estado defenderá el interés de los consumidores y usuarios de cualquier sector del mercado (Quispe, 2007, p. 109), lo que significa una dimensión mayor a la relación de consumo, abarcando el respeto de su personalidad y de sus derechos, a través de la provisión de medios y garantías para ello.

De lo anterior, se desprende que la protección de datos personales, como derecho fundamental,

[9] Congreso Constituyente Democrático, 29 de diciembre de 1993, Constitución Política del Perú.

«Artículo 59. El Estado estimula la creación de riqueza y garantiza la libertad de trabajo y la libertad de empresa, comercio e industria. El ejercicio de estas libertades no debe ser lesivo a la moral, ni a la salud, ni a la seguridad públicas. El Estado brinda oportunidades de superación a los sectores que sufren cualquier desigualdad; en tal sentido, promueve las pequeñas empresas en todas sus modalidades.

[10] Congreso Constituyente Democrático, 29 de diciembre de 1993, Constitución Política del Perú.

«Artículo 62. La libertad de contratar garantiza que las partes pueden pactar válidamente según las normas vigentes al tiempo del contrato. Los términos contractuales no pueden ser modificados por leyes u otras disposiciones de cualquier clase. Los conflictos derivados de la relación contractual solo se solucionan en la vía arbitral o en la judicial, según los mecanismos de protección previstos en el contrato o contemplados en la ley.

$[\ldots] »$.

[11] Sentencia del Tribunal Constitucional recaída en el Exp. N. ${ }^{\circ}$ 03700-2010-PHD/TC, del 7 de agosto de 2014:

6. [...] resulta legítimo y acorde con el derecho a la libertad de contratación, que exista un flujo continuo de información de riegos crediticios en el mercado, pues solo así se puede generar confianza en el sistema financiero para el otorgamiento de créditos y su consiguiente recuperación, en la medida de que el tratamiento de este tipo de datos permite, tanto a personas jurídicas como a personas naturales, conocer el comportamiento en el tiempo de los sujetos de crédito en general (historial crediticio: endeudamiento, capacidad de pago, voluntad de pago), para así tomar decisiones adecuadas en torno al ofrecimiento de créditos, lo cual repercute directamente en la economía nacional (requisitos para el acceso al crédito, tasas de interés, por ejemplo).

[12] Congreso Constituyente Democrático, 29 de diciembre de 1993, Constitución Política del Perú.

«Artículo 65. El Estado defiende el interés de los consumidores y usuarios. Para tal efecto, garantiza el derecho a la información sobre los bienes y servicios que se encuentran a su disposición en el mercado. Asimismo, vela, en particular, por la salud y la seguridad de la población.» 
también actúa en el ámbito del tratamiento de la información crediticia por medio de las disposiciones de la Ley CEPIR, y de forma general en el ámbito de actividades crediticias y/o comerciales, por medio de la norma que la desarrolla transversalmente, que es la LPDP, siendo las dos normas que buscan equilibrar el poder de quien maneja la información, en beneficio de los derechos de sus titulares.

\section{ANTECEDENTES Y CONTENIDO DE LA LEY CEPIR}

Siendo el artículo 160 de la Ley 27602 que posibilita el establecimiento de las CEPIR y en virtud de la circulación de información personal inherente a sus funciones, la Ley CEPIR contiene las precisiones de los objetos de la actividad (el tipo específico de información personal y el producto de su procesamiento sistemático), las operaciones que la componen y sobretodo, los derechos de las personas sobre información crediticia de la cual son titulares.

En tal sentido, es pertinente comenzar el análisis explicando la doble dimensión del objeto de dicha ley, según su artículo 1: La veracidad y el uso apropiado de la información de riesgo en el mercado, junto al respeto a la confidencialidad y a los derechos fundamentales de las personas. Se evidencia la necesidad de equilibrio de los intereses en juego en torno a la información crediticia, entre la injerencia justificada en la información de la persona y la protección de sus datos (Más, op. cit., p. 198), y también de la limitación de funciones, a través de las cosas y acciones a ejercer.

Para tal delimitación, se recurre a las definiciones del artículo 2 de la Ley CEPIR, en cuyo literal b) la información concerniente a la solvencia de las personas se conceptualiza como «información de riesgos", como los datos referidos a obligaciones financieras, comerciales, tributarias, laborales y de seguros, vinculada a su capacidad y trayectoria de pago de una persona $^{[13]}$. Con ello, resulta clara la circunscripción de los datos con los cuales las CEPIR pueden realizar operaciones de tratamiento: datos de índole financiera sobre el comportamiento del sujeto en el mercado, relacionados con la ejecución de sus obligaciones dinerarias (Remolina, 2013, p. 167).

Al respecto, conviene remarcar que esta información no solo es constituida por datos del estado actual, sino también por lo referido a pagos oportunos y deudas vencidas cuyo plazo no exceda los dos años de extintas o cinco desde su vencimiento, pues refleja la trayectoria o «vida crediticia» de una persona, usando los términos de Vilela (2015, p. 28).

Entonces, queda claro también que la esencia de la «información de riesgos» es su utilidad para evaluar el nivel de riesgo crediticio con información del devenir de cada persona, determinante no solo para el otorgamiento adecuado de créditos, sino también por poder o no limitar actividades económicas de las personas naturales.

Ante la diversidad de las fuentes de datos que constituyen «información de riesgos» se requiere su debido tratamiento, actualización y sistematización, la cual es desarrollada por las (CEPIR) con la finalidad de elaborar, como producto de dicha operación de tratamiento, el denominado «reporte de crédito».

El desarrollo de dicha operación, al implicar el tratamiento de información personal de otros tipos, requiere límites con los que se garanticen los derechos fundamentales de las personas, en toda la operación llevada a cabo por la CEPIR, como es la recopilación de información y su posterior entrega. Un primer límite se dio con la definición de «información de riesgos», que demarca el ámbito objetivo del tratamiento, señalando sobre qué ele-

[13] Congreso de la República, 11 de junio de 2001. Artículo 2. Ley N. 27489 , Ley que regula las centrales privadas de información de riesgos y de protección al titular de la información. Diario Oficial El Peruano.

«Artículo 2. Definiciones

Para los efectos de esta Ley, se entiende por:

$[\ldots]$

b) Información de riesgos. Información relacionada a obligaciones o antecedentes financieros, comerciales, tributarios, laborales, de seguros de una persona natural o jurídica que permita evaluar su solvencia económica vinculada, principalmente, a su capacidad y trayectoria de endeudamiento y pago.» 
mentos pueden actuar, excluyendo a los que no sirven a su concepto.

Ahora, es cierto que dicho concepto abarca diversas categorías, pero no todos los datos de una determinada categoría son parte de tal concepto ni deben ser objeto de tratamiento por parte de las CEPIR, como sucede en los records de asistencia de una persona en un determinado empleo o los pormenores de una transacción comercial aislada, al no ofrecer información conducente para el riesgo crediticio de una persona, no deben conformar la masa informativa, resultando su tratamiento, incluso, contrario a la LPDP, como podremos estudiar.

Asimismo, es preciso señalar que dicha operación de tratamiento no significa de ningún modo que la CEPIR esté autorizada a obtener nuevos datos mediante la organización y el perfilamiento, como un perfil crediticio o alguna evaluación de probabilidades; ejercicios que por la ley que regula su actividad no se le permiten, puesto que significa un tratamiento ulterior a la recopilación y sistematización, acciones que componen su función.
El verdadero producto de la operación de las CEPIR, y objeto contractual de esta con sus clientes, es el «reporte de crédito»[14], documento que contiene la información de riesgos de una persona, el cual se entrega a la empresa que evalúa otorgarle un crédito. Dicho reporte tiene un contenido variable según el momento en el que se entregue la información, pues refleja con el comportamiento crediticio del sujeto, hasta el momento de su consolidación.

Corresponde explicar por qué consideramos incorrecto el uso del término «difusión» en el presente artículo, aun siendo incluido en las definiciones de la Ley CEPIR. Consideramos que es un defecto importante de la misma, puesto que el significado del verbo «difundir» presente en el Diccionario de la Lengua Española a cargo de la Real Academia Española implica la divulgación extendida de hechos o información ${ }^{[15]}$, generalmente dirigida a un colectivo o pluralidad, mas no centralizada ni con destinatario específico, significado adoptado en otras normas e, incluso, la Constitución Política del Perú, respecto de valores o derechos de colectividad ${ }^{[16]}$. La ge-

[14] Congreso de la República, 11 de junio de 2001. Artículo 2. Ley N. ${ }^{\circ} 27489$, Ley que regula las centrales privadas de información de riesgos y de protección al titular de la información. Diario Oficial El Peruano.

\section{«Artículo 2. Definiciones}

Para los efectos de esta Ley, se entiende por:

[...]

e) Reporte de crédito. Toda comunicación escrita o contenida en algún medio proporcionada por una CEPIR con información de riesgos referida a una persona natural o jurídica, identificada.»

[15] Diccionario de la Lengua Española, Real Academia Española:

«Difundir: [...] 3. Propagar o divulgar conocimientos, noticias, actitudes, costumbres, modas, etc.». Recuperado de: www.rae.es

(Consulta: 3 de mayo de 2019).

[16] Congreso Constituyente Democrático, 29 de diciembre de 1993, Constitución Política del Perú.

\section{«Artículo 2. Toda persona tiene derecho:}

$[\ldots]$

8. A la libertad de creación intelectual, artística, técnica y científica, así como a la propiedad sobre dichas creaciones y a su producto. El Estado propicia el acceso a la cultura y fomenta su desarrollo y difusión. Artículo 21. Los yacimientos y restos arqueológicos, construcciones, monumentos, lugares, documentos bibliográficos y de archivo, objetos artísticos y testimonios de valor histórico, expresamente declarados bienes culturales, y provisionalmente los que se presumen como tales, son patrimonio cultural de la Nación, independientemente de su condición de propiedad privada o pública. Están protegidos por el Estado. La ley garantiza la propiedad de dicho patrimonio. Fomenta conforme a ley, la participación privada en la conservación, restauración, exhibición y difusión del mismo, así como su restitución al país cuando hubiere sido ilegalmente trasladado fuera del territorio nacional.» 
neralidad del destinatario de la información atenta contra el objetivo vinculado con la protección de la confidencialidad, la cual impide una circulación indiscriminada de información de los titulares.

Lo expuesto encuentra respaldo en el artículo 11 de dicha ley, que si bien establece la permisión de «difundir» la información de riesgos utilizando procedimientos automatizados, utiliza en otra parte del texto términos conceptualmente más apropiados para describir las transmisiones de información en los que se tiene individualizado al destinatario o accedente, como la transmisión, comunicación o acceso a los datos por parte de los terceros.

Luego de la delimitación de la información a tratar, se aprecia en la definición del literal a) de su artículo 2 la demarcación de acciones de tratamiento de información a cargo de las CEPIR. En tal sentido, se distingue dos momentos de tratamiento:

- La recolección y conservación de información de riesgos de personas naturales o jurídicas, que implica su registro y sistematización en reportes de crédito.

- La entrega, por cualquier medio, de tales reportes, que es el propósito de la recolección y tratamiento.

Respecto de la recolección y tratamiento de la información de riesgos, las siguientes interrogantes surgen naturalmente: ¿de dónde extrae la información de riesgo una CEPIR?, ¿bajo qué supuestos se le permite tal extracción?

La Ley CEPIR establece inicialmente un amplio acervo de fuentes y cierto grado de libertad de acción y de adquisición de fuentes, como se aprecia en su artículo 7, que permite la recolección de información de riesgos de fuentes públicas o privadas, mediando una relación contractual en este último caso, y sin la obligación de obtener el consentimiento del titular, siendo esto amparado por la LPDP como se verá en el subtítulo siguiente.

El límite principal a la recolección se encuentra en el literal a) del artículo 9 de la Ley CEPIR, pues recurrir medios fraudulentos o ilícitos, como la comisión de delitos o infracciones, o la toma de la información del mismo titular, mediando elementos que enajenen su voluntad; mientras que en el literal b) de dicho artículo, se restringe la finalidad del tratamiento a la establecida en la misma ley, la elaboración y entrega del reporte de crédito.

Por su parte, el literal c) de dicho artículo establece una obligación de la CEPIR concerniente al contenido de la información, que consiste en preservar la licitud, así como para la actualización, veracidad y exactitud de la información del estado de cada deudor, por medio del establecimiento de medidas correctivas sobre dicha información de forma autónoma, perentorio y de oficio (Casas, 2015, p. 24), más allá del ejercicio de los derechos del titular. Finalmente, el literal d) establece como límite temporal del tratamiento la fecha de la cancelación solicitada de la información, debido a que la ley no estableció expresamente un plazo máximo de su conservación, sino que la condiciona a la voluntad del titular, texto que en cierta forma no compatibiliza con la exigencia de proactividad en la actualización de los datos que se prevé en el literal anterior ${ }^{[17]}$.

[17] Congreso de la República, 11 de junio de 2001. Artículo 2. Ley N. 27489 , Ley que regula las centrales privadas de información de riesgos y de protección al titular de la información. Diario Oficial El Peruano.

Artículo 9. Lineamientos generales de recolección y tratamiento de información

$[\ldots]$

c) La información que deberá constar en los reportes informativos será lícita, exacta y veraz, de forma tal que responda a la situación real del titular de la información en determinado momento. Si la información resulta ser ilícita, inexacta o errónea, en todo o en parte, deberán adoptarse las medidas correctivas, según sea el caso, por parte de las CEPIRS, sin perjuicio de los derechos que corresponden a los titulares de dicha información.

[...]

d) La información será conservada durante el plazo legal establecido en la presente Ley o en su defecto, hasta que se produzca su cancelación conforme a lo prescrito en el inciso b) del artículo 13 de la presente Ley. 
La segunda etapa de las operaciones de la CEPIR implica la entrega de información de riesgos de las personas a las empresas solicitantes (mal llamada «difusión» como ya explicamos), permitida en el artículo 11 de la Ley CEPIR ${ }^{[18]}$ con una obligación esencial que confirma la ratio legis involucrada con la protección de la confidencialidad: Identificar y registrar a quienes se haya remitido dicha información.

¿Contribuye el registro de los destinatarios de la información de riesgos? Sí, puesto que el alcance de tal detalle implica facilitar al titular de los datos su derecho de acceso a los factores que componen la operación de tratamiento de sus datos, como la indicación de las identidades de quienes obtuvieron reportes de crédito concernientes a su persona, como se tiene previsto en el artículo 14 de la Ley CEPIR ${ }^{[19]}$, el cual delinea la forma de ejercer tal derecho.

El mencionado derecho de acceso es uno de los cuales está dotado el titular de información, según el texto del artículo 13 de la mencionada ley, conjuntamente con los de modificación y cancelación de su información, así como de la rectificación y de actualización de la misma; cir- cunscribiéndose la aplicación de cada uno a los siguientes supuestos:

Modificación y cancelación: aplicable solo para la información que figure en el banco de datos de la CEPIR, cuando sea inexacta, ilegal, errónea o caduca, teniendo dicha empresa la obligación de tener implementados los medios y canales para atender las solicitudes, en el plazo común de siete días hábiles, prorrogables hasta por cinco días más, de acuerdo con el artículo 15 de la Ley.

- Rectificación: aplicable a la información entregada por medio de un reporte de crédito a un tercero, cuando sea inexacta, ilegal, errónea o caduca. Si bien opera cuando la información fue transmitida, el artículo 16 de la Ley CEPIR establece la obligación de adoptar medidas correctivas como las comunicaciones rectificatorias.

- Actualización: referida a pagos parciales de las deudas, cuando haya vencido el plazo de vencimiento para que las fuentes otorguen la información a la CEPIR (dos días hábiles), o de los reportes de crédito, una vez recibidos por las entidades crediticias, según se con-

[18] Congreso de la República, 11 de junio de 2001. Artículo 2. Ley N. ${ }^{\circ} 27489$, Ley que regula las centrales privadas de información de riesgos y de protección al titular de la información. Diario Oficial El Peruano.

\section{Artículo 11. Difusión de información de riesgos}

Las CEPIRS podrán difundir a terceras personas, de manera onerosa o a título gratuito, la información de riesgos que contengan en sus bancos de datos. Para tales efectos, las CEPIRS podrán implementar en la forma que estimen convenientes procedimientos automatizados para la transmisión, comunicación o acceso de datos a terceros, así como el registro obligatorio de estos bajo responsabilidad, debiendo cautelar los derechos de los titulares de la información.

Las CEPIRS difunden la información de riesgo, luego de identificar con medios apropiados al solicitante de la información.

[19] Congreso de la República, 11 de junio de 2001. Artículo 2. Ley N. ${ }^{\circ} 27489$, Ley que regula las centrales privadas de información de riesgos y de protección al titular de la información. Diario Oficial El Peruano.

\section{Artículo 14. Derecho de acceso}

Los titulares podrán acceder [...] a la información crediticia que les concierne que estuviese registrada en los bancos de datos administrados por las CEPIRS. [...]

La información a que se refiere este artículo incluirá, a solicitud del titular, la identidad de las fuentes de información registrada en los bancos de datos, con excepción de las fuentes de acceso público y la identidad de todas las personas que obtuvieron un reporte de crédito sobre el titular en los últimos doce meses, así como la fecha en que se emitieron tales reportes. 
templa en los numerales $15.6,15.7$ y 15.8 del artículo 15 de la Ley CEPIR.

Tales derechos demuestran la puesta en práctica de la autodeterminación informativa en el ámbito del tratamiento de información crediticia, en las diversas etapas del mismo y permitiendo oponerla no solo ante el mero almacenamiento de información por parte de la CEPIR, sino cuando la información ya fue remitida, sin que esto le reste a ella responsabilidad sobre la exactitud y veracidad de los productos que entrega, al ser la obligada principal a enmendar y frente a su cliente, en mérito de su relación contractual.

Ahora bien, el título quinto de la Ley CEPIR, referida a la defensa del consumidor, establece que ante la comisión de las infracciones establecidas en el artículo 20 de dicha ley, consistentes en no permitir el ejercicio de los derechos del titular de la información, la entidad competente para llevar el procedimiento sancionador sería la Comisión de Protección al Consumidor del Instituto Nacional de Defensa de la Competencia y de la Propiedad Intelectual (Indecopi), pues dicho titular es considerado en la ley como un consumidor.

Sobre ello, no puede ocultarse que, en efecto, el titular de la información constituye un cliente de las entidades crediticias o de las que efectúen operaciones comerciales a crédito, no siendo tan claro respecto de las CEPIR. En tal circunstancia, debería entenderse que la CEPIR indirectamente provee un bien necesario para que el individuo establezca una relación contractual, el cual es la entrega de información que impulse su acceso a un crédito, proceso en el cual también se debe velar por sus derechos fundamentales.

Entonces, la protección que la Ley CEPIR brinda al titular de la información se fundamenta en el resguardo de la confidencialidad de su información, como en sus derechos como consumidor. Sin embargo, la aplicación de las disposiciones que lo favorecen dan prevalencia al tráfico de la información de riesgos en beneficio del mercado, por lo que la protección de la LPDP y su reglamento tiene un espectro más amplio, al ser una norma transversal, aplicable a la generalidad de actividades, con restricciones que se estudiarán a continuación.

\section{CONTENIDO DE LA NORMATIVA DE PRO- TECCIÓN DE DATOS PERSONALES}

El numeral 6 del artículo 2 de la Constitución requería una ley que lo desarrolle, estableciendo como objeto de protección a la información que identifica o hace identificable a las personas naturales, así como los factores de su adecuado tratamiento por parte de terceros, aparte de establecer procedimientos administrativos alternativos al Habeas Data, rol cumplido por la LPDP desde su publicación en julio de 2011 y gradual vigencia, culminando con la aprobación de su reglamento por medio del Decreto Supremo N. ${ }^{\circ}$ 003-2013-JUS, vigente desde mayo de 2013, que complementa las disposiciones de dicha ley.

En las definiciones de su artículo 2 de la LPDP, conceptualiza a los «datos personales» como toda información que identifica directamente a las personas naturales, por medio de elementos como su nombre o DNI; o que habilita la identificación de tales personas a través de factores como conductas y hábitos de consumo, ingresos y otros bienes, desempeño laboral, estado de salud y entre otros.

En el mismo artículo, se define también al «tratamiento de datos personales» con una lista de actividades o procedimientos de manipulación de datos personales, tales como el mero almacenamiento, la organización, el bloqueo, la supresión, así como diversas modalidades de traslado de dominio, como puede ser la transferencia por comunicación, a destinatarios reconocibles, o por difusión. Dicha lista es enunciativa, permitiendo entender como tratamiento de datos personales a cualquier operación que implique manipulación de datos personales, como la indexación, la evaluación o el perfilamiento, incluyendo dentro de tan amplio espectro, se incorporan a las operaciones de tratamiento efectuadas por las CEPIR.

En dicha normativa, las definiciones establecen los distintos roles que puede tener una entidad que efectúa el tratamiento de datos personales, según su poder de decisión. En el artículo 2 del reglamento de la LPDP, el concepto de «responsable de tratamiento» señala con carácter genérico a toda persona que tenga poder de decisión sobre el tratamiento, estableciendo sus medios, finalidad, estructura, contenido y uso (Dávara Fernández de 
Marcos, 2011, p. 151), sin necesidad de un banco de datos personales ${ }^{[20]}$. Como subordinado del responsable está el encargado del tratamiento, descrito en los numerales 7 y $8^{[21]}$, cuya actividad se limita a las instrucciones del responsable del tratamiento (Lorenzo, 2016, p. 132-133) y a la finalidad que este establezca, de acuerdo con el vínculo contractual que mantengan, figura muy presente en la realidad, al existir la tercerización de operación con entidades más especializadas y con mayores garantías para el tratamiento de datos.

Luego de desarrollados los conceptos de la LPDP, conviene preguntarse si por tener una ley especial, la Ley CEPIR, el tratamiento por parte de los agentes de su sector de mercado se encuentra excluido del ámbito de aplicación de la LPDP. El artículo 3 de dicha ley establece cuatro supuestos de tratamiento de datos personales no cubiertos por sus disposiciones:

- Tratamiento efectuado por personas naturales exclusivo para vida privada y familiar.

- Tratamiento efectuado por una entidad pública, en cumplimiento de sus competencias asignadas por ley relativas a defensa nacional, como los datos personales a cargo del Ministerio de Defensa (Eguiguren, 2015, pp. 134-135).

- Tratamiento efectuado por una entidad pública, en cumplimiento de sus competencias asignadas por ley relativas a seguridad pública.

- Tratamiento efectuado por una entidad pública desempeñando sus competencias legales, para la investigación y represión del delito, como el Ministerio Público, el Poder Judicial y la Unidad de Inteligencia Financiera (Loc. cit.).

Para el debido tratamiento, la LPDP establece principios rectores, los cuales demarcan el camino de corrección de tal tratamiento, cumpliendo una función informadora e integradora para la normativa (Palma, 2018, p. 40), instituyendo los objetivos de la misma, a cumplirse por medio de las disposiciones específicas de dicha ley y en su reglamento; así también, parte de la doctrina los entiende como unos mínimos que deben garantizarse en el tratamiento (Remolina, 2013, pp. 63-64). En tal sentido, el artículo 12 de la LPDP señala que tales principios sirven de criterio interpretativo de sus disposiciones, para suplir una carencia normativa o como parámetro para el desarrollo de sus disposiciones

[20] Presidencia de la República, 21 de marzo de 2013. Artículo 2. Reglamento de la Ley N. 29733 , Ley de Protección de Datos Personales, aprobado por Decreto Supremo N. ${ }^{\circ}$ 003-2013-JUS.

\section{Artículo 2. Definiciones}

Para los efectos de la aplicación del presente reglamento, sin perjuicio de las definiciones contenidas en la Ley, complementariamente, se entiende las siguientes definiciones:

[...]

14. Responsable del tratamiento: es aquel que decide sobre el tratamiento de datos personales, aun cuando no se encuentren en un banco de datos personales.

[21] Congreso de la República, 3 de julio de 2011. Artículo 2. Ley N. ${ }^{\circ}$ 29733, Ley de Protección de Datos Personales. Diario Oficial El Peruano.

\section{Artículo 2. Definiciones}

Para todos los efectos de la presente Ley, se entiende por:

$[\ldots]$

7. Encargado de tratamiento de datos personales. Toda persona natural, persona jurídica de derecho privado o entidad pública que sola o actuando conjuntamente con otra realiza el tratamiento de los datos personales por encargo del titular del banco de datos personales en virtud de una relación jurídica que le vincula con el mismo y delimita el ámbito de su actuación. Incluye a quien realice el tratamiento sin la existencia de un banco de datos personales.

8. Encargo de tratamiento. Entrega por parte del titular del banco de datos personales a un encargado de tratamiento de datos personales en virtud de una relación jurídica que los vincula. Dicha relación jurídica delimita el ámbito de actuación del encargado de tratamiento de los datos personales. 
y las del reglamento; entre ellos, están los de Legalidad, Consentimiento, Finalidad, Proporcionalidad y Calidad[22].

El principio de Legalidad dispone que el tratamiento debe realizarse según lo que la LPDP u otras normas autoricen, o según sea necesario en una relación jurídica lícita (Puyol, 2016, p. 141), vale decir, con respaldo del ordenamiento jurídico. Por consiguiente, prohíbe particularmente la recopilación mediando la comisión de hechos ilícitos (penales o administrativos), así como aquel en el cual se enajena la voluntad del titular de los datos personales contrariando la buena fe, induciendo a error o engaño, lo cual constituye el tratamiento desleal y fraudulento, de acuerdo con Castro (p. 269).
El principio de Consentimiento establece la principal circunstancia que en la LPDP legitima el tratamiento de datos personales por parte de un tercero, que es la obtención del consentimiento de su titular, vale decir, la manifestación de la voluntad favorable del titular. Por supuesto, al entender dicha manifestación equiparable al acto jurídico contemplado en el Código Civil, que crea una situación jurídica entre el titular y el responsable del tratamiento, debe cumplir ciertos requisitos como el de ser libre, no debiendo existir impedimento para manifestar razonadamente el consentimiento, evitando el error, dolo o coacción de cualquier índole (Trujillo, 2018, p. 55), como se aprecia en el artículo 12 del reglamento de la LPDP ${ }^{[23]}$.

[22] Congreso de la República, 3 de julio de 2011. Artículos 4 al 8. Ley N.² 29733, Ley de Protección de Datos Personales. Diario Oficial El Peruano.

Artículo 4. Principio de legalidad

El tratamiento de los datos personales se hace conforme a lo establecido en la ley. Se prohíbe la recopilación de los datos personales por medios fraudulentos, desleales o ilícitos.

Artículo 5. Principio de consentimiento

Para el tratamiento de los datos personales debe mediar el consentimiento de su titular.

Artículo 6. Principio de finalidad

Los datos personales deben ser recopilados para una finalidad determinada, explícita y lícita. El tratamiento de los datos personales no debe extenderse a otra finalidad que no haya sido la establecida de manera inequívoca como tal al momento de su recopilación, excluyendo los casos de actividades de valor histórico, estadístico o científico cuando se utilice un procedimiento de disociación o anonimización.

Artículo 7. Principio de proporcionalidad

Todo tratamiento de datos personales debe ser adecuado, relevante y no excesivo a la finalidad para la que estos hubiesen sido recopilados.

\section{Artículo 8. Principio de calidad}

Los datos personales que vayan a ser tratados deben ser veraces, exactos y, en la medida de lo posible, actualizados, necesarios, pertinentes y adecuados respecto de la finalidad para la que fueron recopilados. Deben conservarse de forma tal que se garantice su seguridad y solo por el tiempo necesario para cumplir con la finalidad del tratamiento.

[23] Presidencia de la República, 21 de marzo de 2013. Artículo 2. Reglamento de la Ley N. ${ }^{\circ} 29733$, Ley de Protección de Datos Personales, aprobado por Decreto Supremo N. ${ }^{\circ}$ 003-2013-JUS.

\section{Artículo 12. Características del consentimiento}

Además de lo dispuesto en el artículo 18 de la Ley y en el artículo precedente del presente reglamento, la obtención del consentimiento debe ser:

1. Libre: sin que medie error, mala fe, violencia o dolo que puedan afectar la manifestación de voluntad del titular de los datos personales.

La entrega de obsequios o el otorgamiento de beneficios al titular de los datos personales con ocasión de su consentimiento no afectan la condición de libertad que tiene para otorgarlo, salvo en el caso de menores de edad, en los supuestos en que se admite su consentimiento, en que no se considerará libre el consentimiento otorgado mediando obsequios o beneficios. 
Dicho artículo reglamentario desarrolla el contenido del numeral 13.5 del artículo 13 de la LPDP $^{[24]}$, referido a los otros requisitos de validez del otorgamiento del consentimiento:

- Expreso e inequívoco: para otorgar el consentimiento es necesaria su manifestación por medio de cualquier conducta afirmativa que lo refleje indubitablemente a través de las manifestaciones clásicas, como la verbal o escrita (en medios digitales o impresos), y que tampoco deje dudas sobre el tratamiento objeto de consentimiento.
Previo: el consentimiento debe otorgarse antes de iniciar la actividad de tratamiento, pues de ser posterior, se tratará de la convalidación de lo ya realizado.

- Informado: requisito de vital importancia, al ofrecer el recurso básico al titular de los datos para formar adecuadamente su voluntad, información del tratamiento que se efectuará, detallando factores especificados en el artículo 18 de la LPDP ${ }^{[25]}$ y en el numeral 4 del artículo 12 de su reglamento[26].

El condicionamiento de la prestación de un servicio, o la advertencia o amenaza de denegar el acceso a beneficios o servicios que normalmente son de acceso no restringido, sí afecta la libertad de quien otorga consentimiento para el tratamiento de sus datos personales, si los datos solicitados no son indispensables para la prestación de los beneficios o servicios.

[24] Congreso de la República, 3 de julio de 2011. Artículo 18. Ley N. ${ }^{\circ}$ 29733, Ley de Protección de Datos Personales. Diario Oficial EI Peruano.

«Artículo 13. Alcances sobre el tratamiento de datos personales

[...]

13.5 Los datos personales solo pueden ser objeto de tratamiento con consentimiento de su titular, salvo ley autoritativa al respecto. El consentimiento debe ser previo, informado, expreso e inequívoco.»

[25] Congreso de la República, 3 de julio de 2011. Artículo 18. Ley N. ${ }^{\circ}$ 29733, Ley de Protección de Datos Personales. Diario Oficial El Peruano.

Artículo 18. Derecho de información del titular de datos personales. El titular de datos personales tiene derecho a ser informado en forma detallada, sencilla, expresa, inequívoca y de manera previa a su recopilación, sobre la finalidad para la que sus datos personales serán tratados; quiénes son o pueden ser sus destinatarios, la existencia del banco de datos en que se almacenarán, así como la identidad y domicilio de su titular y, de ser el caso, del o de los encargados del tratamiento de sus datos personales; el carácter obligatorio o facultativo de sus respuestas al cuestionario que se le proponga, en especial en cuanto a los datos sensibles; la transferencia de los datos personales; las consecuencias de proporcionar sus datos personales y de su negativa a hacerlo; el tiempo durante el cual se conserven sus datos personales; y la posibilidad de ejercer los derechos que la ley le concede y los medios previstos para ello.

$[\ldots]$.

[26] Presidencia de la República, 21 de marzo de 2013. Artículo 2. Reglamento de la Ley N. ${ }^{\circ} 29733$, Ley de Protección de Datos Personales, aprobado por Decreto Supremo N. ${ }^{\circ}$ 003-2013-JUS.

\section{Artículo 12. Características del consentimiento}

Además de lo dispuesto en el artículo 18 de la Ley y en el artículo precedente del presente reglamento, la obtención del consentimiento debe ser:

$[\ldots]$

4. Informado: Cuando al titular de los datos personales se le comunique clara, expresa e indubitablemente, con lenguaje sencillo, cuando menos de lo siguiente:

a. La identidad y domicilio o dirección del titular del banco de datos personales o del responsable del tratamiento al que puede dirigirse para revocar el consentimiento o ejercer sus derechos. 
Ahora bien, es necesario entender que en la LPDP el consentimiento se establece como regla legitimadora principal, mientras otras modalidades son excepciones a la obligación de obtenerlo, previstas en su artículo 14, siendo trascendentes las siguientes ${ }^{[27]}$ :

- Sobre datos personales contenidos o que puedan figurar en bases de datos de acceso público, definidas en el artículo 17 del reglamento de la LPDP, respetando estos los principios contenidos en la LPDP y dicho re- glamento y, de acuerdo con el criterio de la APDP, utilizándolos para la finalidad de creación de la fuente ${ }^{[28]}$.

- Sobre datos personales necesarios para establecer y ejecutar una relación contractual.

- Sobre datos personales que sean necesarios para salvaguardar intereses legítimos del titular, efectuado por el responsable o por el encargado de su tratamiento, como el caso de solicitud de un préstamo, la entidad financiera podrá tratar sin consentimiento del cliente to-
b. La finalidad o finalidades del tratamiento a las que sus datos serán sometidos.
c. La identidad de los que son o pueden ser sus destinatarios, de ser el caso.
d. La existencia del banco de datos personales en que se almacenarán, cuando corresponda.
e. El carácter obligatorio o facultativo de sus respuestas al cuestionario que se le proponga, cuando sea el caso.
f. Las consecuencias de proporcionar sus datos personales y de su negativa a hacerlo.
g. En su caso, la transferencia nacional e internacional de datos que se efectúen.

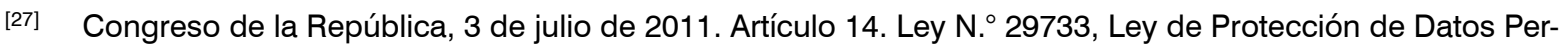
sonales. Diario Oficial El Peruano.

\section{Artículo 14. Limitaciones al consentimiento para el tratamiento de datos personales}

No se requiere el consentimiento del titular de datos personales, para los efectos de su tratamiento, en los siguientes casos:

$[\ldots]$

2. Cuando se trate de datos personales contenidos o destinados a ser contenidos en fuentes accesibles al público.

3. Cuando se trate de datos personales relativos a la solvencia patrimonial y de crédito, conforme a ley. $[\ldots]$

5. Cuando los datos personales sean necesarios para la preparación, celebración y ejecución de una relación contractual en la que el titular de datos personales sea parte, o cuando se trate de datos personales que deriven de una relación científica o profesional del titular y sean necesarios para su desarrollo o cumplimiento.

$[\ldots]$

9. Cuando el tratamiento de los datos personales sea necesario para salvaguardar intereses legítimos del titular de datos personales por parte del titular de datos personales o por el encargado de tratamiento de datos personales. (sic)

[28] Mediante la Opinión Consultiva del Oficio N. ${ }^{\circ}$ 749-2018-JUS/DGTAIPD, la Dirección General de Transparencia, Acceso a la Información Pública y Protección de Datos Personales señaló lo siguiente:

[...] los datos contenidos en las fuentes de acceso al público deben de utilizarse únicamente dentro del marco para el cual dicha fuente ha sido creada y pone a disposición la información mencionada. [...] En caso se requiera realizar tratamientos para finalidades distintas a aquellas para las cuales los datos personales fueron puestos a disposición en las fuentes accesibles al público, como por ejemplo remitir publicidad, deberá solicitarse el consentimiento conforme al artículo 5 y el artículo 13, inciso 13.5, de la LPDP.

Recuperado de: https://www.minjus.gob.pe/wp-content/uploads/2018/10/O-C-38_OCTUBRE.pdf

(Consultado el 16 de mayo de 2019). 
dos sus datos necesarios para evaluar y gestionar la entrega del crédito.

- Sobre datos personales referidos a la solvencia patrimonial y de crédito, en mérito de la ley aplicable, al sector o giro, como la Ley CEPIR.

La no exigibilidad del consentimiento no excusa al responsable de acatar los otros principios rectores. Al beneficiarse con excepciones como las expuestas previamente, el responsable del tratamiento debe alinear su conducta tanto a las disposiciones de la LPDP como a las de dicha norma sectorial, a fin de equilibrar su situación respecto a la del titular de los datos, persistiendo otros deberes, como el de informar al titular sobre su inclusión en la base de datos (Quiepo de Llano, 2010, pp. 66-67) y el de atención de sus derechos.

Justamente, entre aquellos principios rectores se encuentran los de Finalidad y Proporcionalidad, los cuales mencionamos conjuntamente debido a su complementariedad, pues la exigibilidad del segundo depende del contenido del primero, pues este determina los límites que debe preservarse por medio del tratamiento proporcional de datos personales.

El artículo 6 de la LPDP establece como principio que el tratamiento de los datos personales, tanto en su etapa de recopilación como en los siguientes tratamientos, debe realizarse siguiendo únicamente las finalidades lícitas, que hayan sido determinadas explícitamente al momento de su recopilación: deben ser acordes con el ordenamiento jurídico general y haber sido conocidas por los titulares de los datos personales con la mayor especificidad posible, la suficiente para evitar ambigüedades o disensos.

Acerca de ello, debemos anotar que aun siendo obligatorio informar adecuadamente sobre las finalidades del tratamiento, según el artículo 18 de la LPDP, en algunos casos subyacen de la propia actividad del responsable del tratamiento, siendo plenamente inteligibles para el titular de los datos personales, con lo cual, a nuestro entender, se cumple con el requisito de determinación indubitable de aquella finalidad.

Siguiendo la lectura de dicho artículo, se aprecia la prohibición de extender el tratamiento a otras finalidades que no sean aquellas que no hayan estado establecidas inequívocamente al momento de su recopilación (Coz, 2015, p. 34). Esta disposición puede entenderse como restrictiva del tratamiento de datos personales en todos los casos, puesto que se basa no solo en la no obtención del consentimiento para una finalidad determinada, sino que se extiende incluso a aquellos que no requieren tal consentimiento, pero se efectúan sin brindar la información sobre las finalidades al titular de los datos; así también, se puede extender tal interpretación hasta puntos rígidos en los que no se permita el tratamiento ni para finalidades indirectamente vinculadas, subordinadas a la principal o afines.

En este punto, corresponde traer a colación la finalidad del tratamiento de datos personales realizado por una CEPIR, cabiendo preguntarse si resulta indubitable para el titular de los datos. En respuesta, se debe señalar que la Ley CEPIR determina una finalidad general y una específica: La finalidad general consiste en el tratamiento estrictamente de información de riesgos veraz y actual, a fin de contribuir con el mercado crediticio y preservando la confidencialidad de las personas, mientras que la específica consiste en la entrega de reportes de crédito a quien se lo solicite, en el marco de una relación jurídica, la misma que se cumple gracias al desarrollo de la primera.

Siendo lícitas tales finalidades y certeramente determinadas desde el momento de la recopilación de los datos personales, se puede examinar el principio de Proporcionalidad del artículo 7 de la LPDP, que restringe el tratamiento a lo necesario para alcanzar dichas finalidades. La restricción reduce el tratamiento a los datos personales relevantes y adecuados, a los que sean útiles y conducentes a tal finalidad, contribuyendo con la eficiencia y el equilibrio en el tratamiento; al satisfacer tales requisitos, y en caso de la finalidad se alcance con unas determinadas clases y cantidad de datos personales, corresponde evitar actividades de tratamiento u obtención de datos adicionales, inhibiéndose los ejercicios invasivos adicionales para satisfacer una finalidad ya alcanzada.

Consideramos que tales limitaciones son de índole cualitativa, pues no obedecen a una cantidad preestablecida de datos o de clases de datos, 
sino que son determinadas por las necesidades y la naturaleza de cada actividad en la que el tratamiento se desarrolla, lo cual es una cuestión a examinar caso por caso, puesto que los datos que son necesarios para una finalidad, no siempre lo son para otra (Palma, p. 46), aun siendo afín o conexa.

Por dicha razón, ni la LPDP ni su reglamento se refieren a un lapso para el tratamiento más allá del necesario para el cumplimiento de su finalidad o hasta el momento en el que el titular solicite su cancelación, aun cuando pueden tener límites establecidos en ciertas normas especiales, como los datos de salud en historias clínicas o las plasmadas en boletas de pago en ámbito laboral.

Para el desarrollo de tales principios, se tiene la obligación establecida en el numeral 3 del artículo 28 de la LPDP ${ }^{[29]}$, que condensa en un solo texto las características de la finalidad que determina el tratamiento y así como las cualidades de conducencia y no exceso que hacen proporcional al mismo tratamiento, tomando en cuenta la finalidad de estos preceptos, que es frenar el conocimiento excesivo de una determinada persona.

En consonancia con tales principios, se encuentra el de Calidad, contemplado en el artículo 8 de la LPDP. Ya determinados los datos que serán tratados para cumplir con una finalidad determinada, dicho principio busca que la información corresponda a la verdad actual de su titular, que conserve su aptitud identificativa y con ello, su cualidad de «dato personal» y llamando a la eficiencia en el tratamiento de datos personales.

Este principio ya no responde solo a preguntas como «¿Para qué?» o «iHasta dónde?», sino a una como «iEsto aún sirve?», afirmándose en su artículo la necesidad de que se traten datos adecuados, necesarios y pertinentes para la finalidad, añadiendo la exigencia de que estos sean actualizados mientras sea posible para el responsable, a fin de que con su tratamiento mantenga pertinencia respecto a la actividad determinada como su finalidad, debiendo conservarse mientras guarde utilidad para alcanzar su finalidad.

Dicha situación implica que para suplir la deficiencia informativa, el responsable debe facilitar medios para el ejercicio simple de los derechos de acceso, rectificación, cancelación y oposición al tratamiento, a ser atendidos en los plazos señalados en el artículo 65 del Reglamento de la LPDP. Así también, debe desplegar medidas particulares dispuestas de oficio (Dávara, 2015, p. 86) para que sus registros de datos personales mantengan correspondencia con la realidad actual de cada persona, debiendo verificar la continuidad de su pertinencia, para cesar su conservación cuando no sea necesario el tratamiento.

Es interesante apreciar que la LPDP, como norma transversal, otorga a los titulares de datos personales los medios para el ejercicio de sus derechos ante todo tratamiento por parte del tercero, de lo cual surgen obligaciones específicas a cargo del responsable del tratamiento, que es la CEPIR. Para el caso de la información de riesgos, la Ley CEPIR tiene previstos derechos que son ejercidos ante Indecopi, siendo competencia de la APDP evaluar el debido tratamiento de otros datos personales, como en el caso de Sentinel, estudiado a continuación.

\section{PRONUNCIAMIENTOS DE LA APDP EN EL CASO SENTINEL (EXPEDIENTE N. ${ }^{\circ}$ 087- 2018-JUS/DPDP-PS)}

En atención a una denuncia presentada el 1 de marzo de 2018, mediante la Resolución Directoral N.ํ 131-2018-JUS/DGTAIPD-DFI, la Dirección de

[29] Congreso de la República, 3 de julio de 2011. Artículo 14. Ley N. ${ }^{\circ}$ 29733, Ley de Protección de Datos Personales. Diario Oficial El Peruano.

«Artículo 28. Obligaciones

El titular y el encargado de tratamiento de datos personales, según sea el caso, tienen las siguientes obligaciones:

[...]

3. Recopilar datos personales que sean actualizados, necesarios, pertinentes y adecuados, con relación a finalidades determinadas, explícitas y lícitas para las que se hayan obtenido.» 
Fiscalización e Instrucción de la Dirección General de Transparencia, Acceso a la Información Pública y Protección de Datos Personales (autoridad fiscalizadora e instructora de este caso), inició el procedimiento sancionador, imputando las siguientes presuntas infracciones:

- Recopilar en su banco de datos personales y difundir en el reporte de crédito, la imagen y fecha de nacimiento, lo cual sería desproporcionado para cumplir con la finalidad de identificar a los titulares de la información y evaluar su solvencia, incumpliendo con los artículos 7, 6 y 28 (numeral 3) de la LPDP; lo que configuraría la infracción leve tipificada en el literal b) del numeral 1 del artículo 132 del Reglamento de la LPDP.

- Recopilar en su banco de datos personales y difundir en el reporte de crédito, la imagen y fecha de nacimiento sin recabar el consentimiento de sus titulares, según lo establecido en los artículos 5 y 13 (numeral 13.5) de la LPDP y en el artículo 12 del reglamento de dicha ley; lo cual configuraría la infracción grave tipificada en el literal b) del numeral 2 del artículo 132 de dicho reglamento.

En su descargo, Sentinel alegó en los siguientes sentidos:

- La Superintendencia de Banca y Seguros determina la capacidad de pago de cada deudor, siendo uno de los criterios utilizados para ello la edad, por lo que su recopilación no vulnera el principio de Proporcionalidad.

- La Ley N. ${ }^{\circ} 26702$ y la Ley del Registro de Deudores Alimentarios autoriza el uso de medios razonables para la identificación de usuarios, como sus imágenes; motivo por el cual incluyen ese dato personal en sus reportes de crédito.

- La fecha de nacimiento constituye información de riesgo por ser un factor importante para determinar el riesgo crediticio. Para sostener las imputaciones al respecto, la autoridad debe demostrar que es un dato irrelevante.

- No se ha demostrado la no idoneidad del uso de la imagen para la identificación de la per- sona, ni se ha establecido qué medio sí sería adecuado.

- La imagen es un dato identificativo imprescindible, al figurar en el DNI de las personas.

Mediante la Resolución Directoral N. ${ }^{\circ}$ 2592019-JUS/DGTAIPD-DPDP, la DPDP sancionó a Sentinel con la multa de 3 UIT por la inobservancia de los principios de Finalidad y Proporcionalidad, en incumplimiento de los artículos 6 y 7 y del numeral 3 del artículo 28 de la LPDP; y con la multa de 15 UIT por la inobservancia del principio de Consentimiento, en incumplimiento del artículo 5 y del numeral 13.5 del artículo 13 de la LPDP. Dicha resolución directoral fue confirmada por la DGTAIPD, por medio de su Resolución Directoral N. ${ }^{\circ} 26$ 2019-JUS/DGTAIPD.

\section{Resolución de la DPDP}

La DPDP, en su Resolución Directoral N. ${ }^{\circ} 259$ 2019-JUS/DGTAIPD-DPDP, dilucidó una cuestión previa sobre la naturaleza del servicio que brinda la CEPIR (considerandos 33 al 38), sin negar su importancia para la confianza en el mercado al suministrar información pertinente, al demarcar que, de acuerdo con la Ley CEPIR, su labor debe ser la recolección y tratamiento de información de riesgos, lo cual sirve como insumo para elaborar el reporte de crédito, una de las herramientas informativas de las que se sirven las entidades crediticias para determinar si otorgan crédito o no a una persona, no siendo la CEPIR la entidad que realiza la evaluación crediticia, sino la entidad usuaria del reporte de crédito.

En atención a los principios de Finalidad y Proporcionalidad, y a la obligación del numeral 3 del artículo 28 de la LPDP, se establece en el considerando 45 de dicha resolución directoral que la finalidad del tratamiento de datos personales realizado por las CEPIR está prevista en su ley, y es únicamente la relacionada a la entrega de reportes de crédito, que requiere de la correcta identificación de la persona. Por ello, en virtud también del principio de Calidad de la LPDP, se permite el tratamiento de datos ajenos a la información de riesgos para identificar a las personas, evitando recabar datos de personas ajenas, en beneficio del correcto servicio de la CEPIR y consiguientemente, de la circulación de información adecuada. 
Conociendo que el reporte de crédito obtenido y entregado por Sentinel contiene tanto el número del DNI (señalado en la resolución directoral como «Código Único de Identificación») y la imagen de cada persona, la DPDP efectúa un examen de la proporcionalidad del tratamiento de tal imagen para identificar a las personas, lo cual es identificado por la DPDP como una finalidad específica involucrada al tratamiento de información crediticia. Al respecto, Sentinel sostuvo que era imprescindible efectuar el tratamiento sobre la imagen aun cuando tuviese el número de DNI de la persona, al ser un dato identificativo fehaciente, por lo cual muchos otros registros de deudores lo contienen.

No obstante a tal argumentación, la DPDP adoptó los criterios de la suficiencia y mayor preponderancia para la identificación que tiene el número de DNI, señalando en sus considerandos 50 y 51 que el artículo 31 de la Ley N. ${ }^{\circ} 26497$, Ley Orgánica del Registro Nacional de Identidad y Estado Civil, establece que el número del DNI (o «Código Único de Identificación») ${ }^{[30]}$ es un elemento que una vez asignado a una persona constituye su único referente identificativo invariable hasta su fallecimiento, siendo irrepetible y permanente, por lo que sin importar lo que suceda con otros datos, este es el único que siempre será vinculado a una sola persona, siendo suficiente para la identificación certera de ella.

No sucede lo mismo en el caso de la imagen, pues a criterio de la DPDP (desarrollado en los considerandos 52 y 53 de su resolución) carece de invariabilidad, pudiendo llegar a mutar tanto en ciertos casos que ya no serviría para identificar certeramente a una persona determinada, por lo que tampoco es funcional para la finalidad señalada en este caso, resultando su tratamiento no proporcional y contrario a la LPDP y su tratamiento. En tal sentido, se declaró no proporcional el tratamiento de la imagen por parte de Sentinel, lo que implica la comisión de la infracción imputada.

Este criterio de la DPDP permitiría a las CEPIR efectuar el tratamiento de un dato personal siempre que sea totalmente conducente, funcional y necesario para la identificación de la persona sujeta a evaluación, pese a exceder el concepto de «información de riesgos», como es el número de DNI. Aun cuando parece obvia la necesidad de identificación en los reportes de crédito es necesario remarcarla a fin de dar flexibilidad a la prohibición de tratamiento de datos personales «para finalidades que no hayan sido claramente establecidas», solo hasta el punto de lo esencial de dicha «subfinalidad», en la medida que constituya un prerrequisito para el cumplimiento de la finalidad principal de este tratamiento de datos personales.

De otro lado, se declaró la atipicidad respecto de la difusión de datos personales, toda vez que la DPDP, según señala en el considerando 61 de su resolución, considera a la difusión una acción diferente a la entrega del reporte de crédito a una entidad determinada, pues como se estableció anteriormente, la difusión implica una entrega de información a una colectividad de destinatarios no identificados.

Ahora bien, respecto a la segunda infracción imputada, referida al tratamiento de datos personales (imagen y fecha de nacimiento) sin obtener de sus titulares el consentimiento de forma válida, la DPDP toma en cuenta que en virtud del cumplimiento de las labores encomendadas por la Ley CEPIR, está legitimada a efectuar el tratamiento de datos personales necesarios para la correcta emisión de reportes de crédito, por medio de la identificación de las personas, siendo esta una finalidad lícita que se seguía por medio del tratamiento de imágenes (más allá de su carácter desproporcionado), por lo que no requiere del consentimiento,

[30] Congreso de la República, 28 de junio de 29915. Artículo 31. Ley N. 27489, Ley Orgánica del Registro Nacional de Identificación y Estado Civil. Diario Oficial El Peruano.

Artículo 31. El Documento Nacional de Identidad (DNI) es otorgado a todos los peruanos nacidos dentro o fuera del territorio de la República desde la fecha de su nacimiento y a los que se nacionalicen, desde que se aprueba el trámite de nacionalización. El documento emitido deberá asignar un Código Único de Identificación el mismo que se mantendrá invariablemente hasta el fallecimiento de la persona, como único referente identificatorio de la misma. 
como se especifica en el considerando 68 de su resolución directoral.

En sentido contrario, la fecha de nacimiento, al revelar la edad, dejaba conocer un dato personal que Sentinel considera necesario por tratarse de un factor de riesgo necesario para efectuar la evaluación crediticia de los clientes, por lo cual es recopilado en sus bases de datos y transmitido en los reportes de crédito. Sobre tal dato personal, la DPDP descartó su cualidad identificativa, así como también el que se trate de una información de riesgos que deba ser tratada por una CEPIR sin consentimiento de su titular, puesto que tampoco se encuadra en el supuesto del numeral 3 del artículo 14 de la LPDP, señalando también que la recopilación de factores de riesgo no es avalada por la Ley CEPIR ${ }^{[31]}$, no estando autorizadas para tal tratamiento, como se indica en los considerandos 73 y 74 de su resolución directoral.

Por su parte, al haber argumentado Sentinel que no requiere consentimiento para tratar la fecha de nacimiento por tomarla de fuentes de acceso público, la DPDP analiza las finalidades de las bases de datos de las que extrae tal dato, esclareciendo que la finalidad del banco de datos de Essalud es acreditar la pertenencia de sus asegurados a ciertos gremios laborales, mientras que el de Susalud se centra en la recepción de denuncias por servicios de salud, a fin de evidenciar que el tratamiento de los datos personales efectuado por Sentinel, al no vincularse con estas finalidades, sí requería el consentimiento de los titulares de los datos personales, como desarrolla en los considerandos 82 al 84 de su resolución directoral.

\section{Resolución de la DGTAIPD}

Ante lo resuelto por la DPDP, Sentinel presentó un recurso de apelación, basado en los siguientes argumentos:
- La imagen es un dato identificativo, por lo que es necesario y proporcional su tratamiento para las finalidades legítimas.

- El tratamiento de la fecha de nacimiento obedece la finalidad de identificar a los titulares de la información, constituyendo información de riesgo sujeta a evaluación crediticia.

- No se ha sustentado que la edad no sea relevante para operaciones crediticias, siendo algo que incluso se ha incluido en la resolución impugnada.

- Al realizarse el tratamiento de dichos datos en la etapa precontractual, no requiere el consentimiento, de acuerdo con el numeral 5 del artículo 14 de la LPDP.

En su Resolución Directoral N. ${ }^{\circ}$ 26-2019-JUS/ DGTAIPD, la DGTAIPD evalúa la finalidad consignada en el banco de datos personales de Información de Riesgos de Sentinel y, como se lee en sus considerandos 24 al 28, señalado que la misma debe circunscribirse a los establecido en la Ley CEPIR, la cual proscribe el tratamiento de datos personales que «no sean idóneos para brindar información que permita la evaluación de solvencia económica vinculada, principalmente, a su capacidad y trayectoria de endeudamiento y pago", no pudiendo ser establecida dicha finalidad por el «sentido común» (considerandos 30 y 31).

En lo concerniente a la finalidad de verificar la identidad de las personas, señalada por la DPDP en la resolución directoral recurrida, la DGTAIPD acepta que constituye un paso necesario para el cumplimiento de la única finalidad auténtica, sin que no una finalidad en sí misma independiente, debiendo realizarla para prestar un servicio idóneo. Entonces, aun siendo un medio para alcanzar la finalidad, no se permite una recopilación invasiva y desproporcional para tal finalidad, llegando en

[31] Congreso de la República, 11 de junio de 2001. Artículo 2. Ley N. ${ }^{\circ} 27489$, Ley que regula las centrales privadas de información de riesgos y de protección al titular de la información. Diario Oficial El Peruano.

Artículo 7. Fuentes de información

7.1 Las CEPIRS podrán recolectar información de riesgos para sus bancos de datos tanto de fuentes públicas como de fuentes privadas, sin necesidad de contar con la autorización del titular de la información, entendiéndose que la base de datos se conformará con toda la información de riesgo. 
caso contrario, al absurdo de permitir el acceso a cualquier dato que sea útil para la verificación de identidad (considerando 43).

Respecto del sujeto que debe asumir dicha carga, la DGTAIPD señala adecuadamente que la misma corresponde en realidad al usuario o cliente de la CEPIR, la empresa crediticia que, al ser el responsable y principal interesado en realizar las evaluaciones crediticias, es quien debe conjurar el riesgo con sus propios medios. Así, la DGTAIPD señala que si bien la fecha de nacimiento entraría en la evaluación crediticia, no compone el concepto de «información de riesgos», sino que se analiza luego de la intervención de la CEPIR.

Finalmente, la DGTAIPD hace una salvedad necesaria: No existe un vínculo contractual entre la persona y la CEPIR que lo exima de la obligación de obtener el consentimiento. El vínculo a establecer con el sujeto a evaluación es de la empresa cliente de la CEPIR, que necesita del reporte de crédito para completar la evaluación de su potencial contraparte.

Sobre la base de dichos argumentos, se declaró infundada la apelación, confirmando las sanciones impuestas por el tratamiento no proporcionado de la imagen de las personas y por el tratamiento de la fecha de nacimiento sin haber obtenido el consentimiento de sus titulares.

\section{A MODO DE CONCLUSIONES}

A lo largo del presente artículo, se apreciaron claramente los intereses constitucionales que interactúan en el ámbito del tratamiento de información de riesgos crediticios, como son el bienestar del individuo, garantizado a través de la protección de sus datos personales y derechos fundamentales conexos, y el correcto tratamiento de dicha información, como coadyuvante para el crecimiento del mercado a través del acceso adecuado al crédito.

La Ley CEPIR surge de la existencia del riesgo de un tratamiento excesivo de información, rebasando lo crediticio, cuyo objetivo radica en restringir el tratamiento a información veraz y exacta, evitando las conductas invasivas y perjudiciales para las personas titulares de información crediticia. Dicha ley, al definir los objetos a manejar (información de riesgos y reportes de crédito) sobre los cuales se desarrolla las actividades de las CEPIR, establece sus límites de acción, circunscribiéndolos a información sobre la solvencia patrimonial para con las obligaciones dinerarias; en mérito de ello, impone deberes a las CEPIR, respecto de la exactitud y actualidad de dicha información, así como a la atención de los derechos de los titulares de información de riesgos.

Por su parte, ante la necesidad de controlar el tránsito de datos de carácter personal y el riesgo que ello implica para la intimidad e inviolabilidad de la persona, la LPDP establece un conjunto de principios cuya finalidad es la realización del debido tratamiento de los datos personales, respaldando el derecho fundamental contenido en el numeral 6 del artículo de la Constitución. Tales principios son desarrollados a través de las restantes disposiciones de dicho texto legal, así como en su reglamento, estableciendo obligaciones para el responsable del tratamiento de datos personales y de cualquier otro que intervenga sin importar su título, así como los derechos que asisten al titular respecto del tratamiento de sus datos personales, de forma similar a los derechos que premune la Ley CEPIR a los titulares de la información.

Es notable cómo la transversalidad de la LPDP alcanza a las CEPIR, sin que la derogue o se yuxtaponga a su ley, por su orientación a la protección del derecho fundamental en la casi totalidad de ámbitos de la actividad pública o privada, complementándola o más bien reforzándola en su objetivo de restringir el tratamiento excesivo de datos personales, al ir más allá de lo que concierne a la información de riesgos, pues la LPDP tiene como finalidad resguardar la integridad de la persona a través de la protección de sus datos.

Dicha situación explica la competencia de la ADPD en un caso de tratamiento por parte de una CEPIR, para examinar el cumplimiento de la Ley CEPIR por parte de estas, en su conceptualización de la información de riesgos, y de los principios de la LPDP aplicables al caso, como se demuestra en sus pronunciamientos, con los cuales se busca proteger a la persona y a sus derechos fundamentales, y contribuir a la fluidez de información crediticia relevante. La APDP no ve un conflicto normativo en el caso de Sentinel, sino que es consciente de la ge- 
neralidad de la LPDP, así como de la aplicación de la Ley CEPIR en lo que concierne a la calificación de datos como información de riesgos.

Por tales motivos, el caso Sentinel es ilustrativo respecto de la comunidad de las finalidades de la Ley CEPIR y la LPDP, en lo que concierne a la protección de los datos personales de los potenciales clientes crediticios, garantizando sus derechos en el contexto de la sociedad de la información y la economía de mercado.

\section{REFERENCIAS BIBLIOGRÁFICAS}

Blossiers Mazzini, J. J. (2013). Manual de Derecho Bancario. 2. a edición. Lima: Editorial y Distribuidora Ediciones Legales E.I.R.L.

Casas Chardón, J. (2015). CEPIR: En Torno a la Procedibilidad de una Solicitud de Revisión de Datos Personales para Efectos de su Tutela Efectiva. En Diálogo con la Jurisprudencia, N. ${ }^{\circ}$ 201, pp. 21-25.

Castro Cruzatt, K. (2008). El Derecho Fundamental a la Protección de Datos Personales: Aportes para su Desarrollo en el Perú. lus et Veritas. Vol. 18, N. ${ }^{\circ} 37$. Lima, pp. 260-277.

Chanamé Orbe, R. (2013). Constitución Económica. Derecho \& Sociedad, N. ${ }^{\circ} 40$. Lima, pp. 43-63.

Coz Barón, D. (2015). El Principio de Finalidad en la Recopilación y Tratamiento de Datos Personales. En Diálogo con la Jurisprudencia, N. ${ }^{\circ} 201$, pp. 33-36.

Dávara Fernández de Marcos, I. (2011). Hacia la Estandarización de la Protección de Datos Personales. Madrid: Editorial La Ley.

Dávara Rodríguez, M. A. (2015). Manual de Derecho Informático. Undécima edición. Navarra: Editorial Aranzadi S.A.

Fernández Sessarego, C. (2004). Derecho de las Personas. Exposición de Motivos y Comentarios al Libro Primero del Código Civil Peruano. 9. ${ }^{a}$ ed. Lima: Editorial y Librería Jurídica Grijley E.I.R.L.

Figueroa Bustamente, H. (2010). Derecho del Mercado Financiero. Lima: Editorial y Librería Jurídica Grijley E.I.R.L.
Kresalja Roselló, B. y Ochoa Cardich, C. (2012). El Régimen Económico de la Constitución de 1993. Lima: Fondo Editorial de la Pontificia Universidad Católica del Perú.

Lete del Río, J. M. (1996). Derecho de la Persona. Madrid: Editorial Tecnos, S.A.

Lorenzo Cabrera, S. (2018). Posición Jurídica de los Intervinientes en el Tratamiento de Datos Personales. En MURGA FERNÁNDEZ, Juan Pablo, FERNÁNDEZ SCAGLIUSI, María de los Ángeles y ESPEJO LERDO DE TEJADA, Manuel (directores). Protección de Datos, Responsabilidad Activa y Técnicas de Garantía. Madrid: Editorial Reus, S.A.

más badía, M. D. (2017). Los Ficheros de Solvencia Patrimonial y Crédito en España: Algunas Cuestiones Pendientes. En PLAZA PENDÉS, Javier y MARTÍNEZ VELENCOSO, Luz (directores). Nuevos Retos Jurídicos de la Sociedad Digital. Navarra: Editorial Aranzadi, S.A.

Palma Ortigosa, A. (2018). Principios Relativos al Tratamiento de Datos Personales. En MURGA FERNÁNDEZ, Juan Pablo, FERNÁNDEZ SCAGLIUSI, María de los Ángeles y ESPEJO LERDO DE TEJADA, Manuel (Directores). Protección de Datos, Responsabilidad Activa y Técnicas de Garantía. Madrid: Editorial Reus, S.A.

Pérez Luño, A. E. (1996). Manual de Informática y Derecho. Barcelona, Editorial Ariel.

Puyol Montero, J. (2016). Los Principios del Derecho a la Protección de Datos. En PIÑAR MAÑAS, José Luis (director). Reglamento General de Protección de Datos. Hacia un Nuevo Modelo Europeo de Privacidad. Madrid: Editorial Reus, S.A.

Quiepo De Llano Giménez, G. (2000). Excepciones al Consentimiento en Ficheros de Titularidad Privada. Especial Referencia al Tratamiento de la Información sobre Solvencia Patrimonial y Crédito. En DÁVARA RODRÍGUEZ, Miguel Ángel (coordinador). XIII Encuentros sobre Informática y Derecho. Navarra: Editorial Aranzadi, S.A.

Quispe Correa, A. (2007). La Constitución Económica. 2. ${ }^{a}$ ed. Lima: Alfredo Quispe Correa. 
Remolina Angarita, N. (2013). Tratamiento de Datos Personales: Una Aproximación Internacional y Comentarios a la Ley 1581 de 2012. Bogotá: Editorial Legis S.A.

Trujillo Cabrera, C. (2018). Las Bases de Legitimación del Tratamiento de Datos Personales. En Especial, el Consentimiento. En MURGA FERNÁNDEZ, Juan Pablo, FERNÁNDEZ SCAGLIU-
SI, María de los Ángeles y ESPEJO LERDO DE TEJADA, Manuel (directores). Protección de Datos, Responsabilidad Activa y Técnicas de Garantía. Madrid: Editorial Reus, S.A.

Vilela Carbajal, J. E. (2015). A Propósito de la Información que Debe Contener el Reporte de las Centrales de Riesgos. En Diálogo con la Jurisprudencia, N. ${ }^{\circ} 201$, pp. 27-32. 